\title{
Prevention of preterm delivery: current challenges and future prospects
}

\author{
This article was published in the following Dove Press journal: \\ International Journal of Women's Health \\ 31 October 2016 \\ Number of times this article has been viewed
}

\author{
Maud D van Zijl' \\ Bouchra Koullali' \\ Ben WJ Mol${ }^{2}$ \\ Eva Pajkrt ${ }^{1}$ \\ Martijn A Oudijk' \\ 'Department of Obstetrics and \\ Gynaecology, Academic Medical \\ Center, Amsterdam, the Netherlands; \\ ${ }^{2}$ The Robinson Research Institute, \\ School for Reproductive Health and \\ Pediatrics, University of Adelaide, \\ Adelaide, SA, Australia
}

\begin{abstract}
Preterm birth (PTB), defined as delivery at $<37$ weeks of gestation, is the most important cause of neonatal morbidity and mortality. Therefore, preventing PTB is one of the main goals in obstetric care. In this review, we provide an overview of the current available literature on screening for risk factors for PTB and a summary of preventive strategies in both low-risk and high-risk women with singleton or multiple gestations. Furthermore, current challenges and future prospects on PTB are discussed. For an optimal prevention of PTB, risk stratification should be based on a combination of (maternal) risk factors, obstetric history, and screening tools. Cervical length measurements can help identify women at risk. Thereafter, preventive strategies such as progesterone, pessaries, and cerclage may help prevent PTB. Effective screening and prevention of PTB vary between the different pregnancy populations. In singleton or multiple pregnancies with a short cervix, without previous PTB, a pessary or progesterone might prevent PTB. In women with a (recurrent) PTB in the past, progesterone and a cerclage may prevent recurrence. The effect of a pessary in these high-risk women is currently being studied. A strong collaboration between doctors, patients' organizations, pharmaceutical companies, and (international) governments is needed to reduce the morbidity and mortality as a result of spontaneous PTB.
\end{abstract}

Keywords: preterm birth, prevention, risk factors, current challenges, future prospects

\section{Introduction}

Preterm birth (PTB), defined as delivery at $<37$ weeks of gestation, is the most important cause of neonatal morbidity and mortality. ${ }^{1,2}$ Two-thirds of PTBs are spontaneous, and one-third comprises induced PTB for medical reasons, mainly preeclampsia and/or fetal growth restriction. ${ }^{3}$ The estimate of 13 million preterm infants born each year worldwide is most probably an underestimation, as most countries have an incomplete birth registration. The risk of neonatal morbidity and mortality is inversely related to gestational age at delivery. ${ }^{4,5}$ Children who are born preterm often have short-term morbidities such as respiratory difficulties (infant respiratory distress syndrome), periventricular leukomalacia, intracranial hemorrhage, bronchopulmonary dysplasia, patent ductus arteriosus, necrotizing enterocolitis, retinopathy of prematurity, and infection. ${ }^{6,7}$ In the long term, many of these children suffer from neurological and developmental disabilities. ${ }^{8}$ Apart from the medical sequela of PTB, prematurity also has large economic consequences.

In an English hypothetical cohort, total costs of PTB in the public sector were estimated to be 4.567 billion US dollars. The costs per surviving child decreased when the gestational age in weeks was higher. The estimated incremental costs per preterm child surviving to 18 years compared to a term survivor were 35.471 US dollars. These costs were significantly higher in the extreme premature group. ${ }^{9}$
Correspondence: Martijn A Oudijk Department of Obstetrics and Gynaecology, Academic Medical Center, Meibergdreef 9, I 105 AZ Amsterdam, the Netherlands

Tel +3I 205667204

Email m.a.oudijk@amc.nl
International Journal of Women's Health 2016:8 633-645

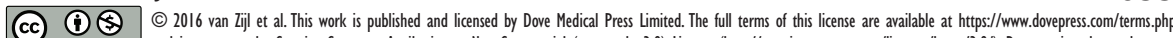
cc. hereby accept the Terms. Non-commercial uses of the work are permitted without any further permission from Dove Medical Press Limited, provided the work is properly attributed. For permision for commercial use of this work, please see paragraphs 4.2 and 5 of our Terms (https://www.dovepress.com/terms.php). 
Prevention of PTB remains as one of the main goals in the obstetric care. ${ }^{3}$ The United Nations Millennium Development Goal 4 targeted two-thirds reduction of under-five deaths between 1990 and 2015, but this goal was not reached. However, the mortality rate has declined by more than half, ${ }^{10}$ possibly due to several interventions to prevent PTB that were introduced in the past decades. Both mechanical interventions such as a cerclage or a cervical pessary and pharmacological interventions using progesterone were evaluated on a large scale.

This review provides an overview of the current available literature on screening and prevention of PTB categorized by several risk groups. This overview helps clinical caregivers to identify women at risk for PTB and provides information on the best preventive strategies to prevent PTB. Furthermore, future prospects of the authors on prevention of spontaneous PTB are discussed.

\section{Risk factors}

The first step in the prevention of PTB is accurate risk assessment and screening for risk factors for a preterm delivery. PTB is a complex syndrome in which various risk factors play an important role. Risk factors for PTB can be divided into following categories:

- maternal risk factors: ethnicity, high or low maternal body mass index (BMI), smoking, and maternal periodontal disease;

- maternal medical history: uterine abnormalities and prior excisional cervical procedures;

- obstetric history: previous curettage, previous PTB;

- current pregnancy: pregnancy interval and multiple gestations.

In addition to these risk factors, bacterial vaginosis, short cervical length, and positive fetal fibronectin could be used as screening targets to identify women at risk for PTB.

\section{Maternal risk factors}

\section{Ethnicity}

There are ethnic disparities in the risk for PTB. A metaanalysis by Schaaf et $\mathrm{al}^{11}$ indicated a higher risk of PTB among non-White women (odds ratio [OR] 2.0; 95\% CI 1.8-2.2) compared to Caucasian women. In contrast, adverse neonatal outcomes were significantly lower in African women compared to the Caucasian women. ${ }^{12}$ Future research should take these figures into account, especially when testing interventions that may have different effects among different ethnic populations.

\section{Extreme high or low maternal BMI}

Women at the extremes of pre-pregnancy BMI are at higher risk for PTB. ${ }^{13}$ Women with an extreme low BMI $\left(<17 \mathrm{~kg} / \mathrm{m}^{2}\right)$ have a significantly higher risk of spontaneous PTB (OR 2.4; 95\% CI 1.4-4.2). An explanation for this could be that chronic maternal undernutrition causes a deficiency in both macro- and micronutrients. This influences the normal fetal growth process negatively. Moreover, nutritional elements such as iron and zinc are essential for an adequate immune system. A deficiency possibly leads to increased susceptibility to infection and therefore a higher risk for PTB. ${ }^{14}$ In women with an extremely high BMI $\left(\geq 35 \mathrm{~kg} / \mathrm{m}^{2}\right)$, this risk is increased due to a higher chance for premature rupture of the membranes (OR 1.6; 95\% CI 1.1-2.3). It is hypothesized that higher number of circulating inflammatory agents in obese women contributes to a higher chance of premature rupture of the membranes. Public campaigns should inform the public on this association, and this information should be used in preconception counseling.

\section{Smoking}

Smoking during pregnancy is a well-known risk factor for PTB. Around 1960, the first articles already described a relationship between smoking cigarettes and prematurity rates. ${ }^{15,16}$ Since then large prospective studies have shown the correlation between smoking and prematurity. ${ }^{17}$ A comparative cohort study showed highest rates of PTB in women who were smoking during pregnancy (OR 3.21; 95\% CI 1.42-7.23) compared to women who stopped smoking during pregnancy and nonsmokers. ${ }^{18}$ Over the past years, governments invested in public campaigns against smoking. A recent meta-analysis revealed a significant drop in the number of PTBs since the smoke-free legislation $(-10.4 \%$; $95 \% \mathrm{CI}-18.8$ to -2.0$) .{ }^{19}$ In many countries, recently a reduction is seen in the number of smokers. This indicates that behavioral strategies (eg, education, rules, and legislation) can help in preventing PTB. Further awareness campaigns may decrease the smoking-associated PTB rate.

\section{Maternal periodontal disease}

Periodontal disease is associated with spontaneous PTB. ${ }^{20}$ Remote site infections, such as in periodontal disease, might trigger PTB because of hematogenous spread of pathogens, inflammatory cytokines, and organisms. ${ }^{21}$ It is hypothesized that treatment of periodontal disease during pregnancy might reduce PTB and improve perinatal outcomes. However, inconclusive findings have been reported. In an obstetrics and 
periodontal therapy study, a randomized controlled trial (RCT) comprising 823 women observed no reduction of PTB in the group of women treated for periodontal disease (OR 0.93; 95\% CI 0.63-1.73). ${ }^{22}$ A more recent RCT by Newnham et al ${ }^{23}$ had similar observations (OR 1.05 ; 95\% CI $0.7-1.58$ ). In conflict, a large meta-analysis in the same year including 2,663 patients reported a reduction in PTB rates (OR 0.55; 95\% CI $0.35-0.86$ ) in the treatment group. ${ }^{24}$ However, the trial by Newnham et al was not included in this meta-analysis. Routine treatment of periodontal disease during pregnancy to prevent PTB is not recommended, but further studies to evaluate the possible benefits from periodontal treatment before conception should be performed.

\section{Maternal medical history}

\section{Uterine anomalies}

Uterine anomalies such as uterine septum, unicornuate uterus, uterine didelphys, and bicornuate uterus are known to be associated with PTB. A retrospective cohort study comprising 203 singleton gestations in women with a uterine anomaly reported a significantly higher risk of spontaneous PTB $<37$ weeks compared to women with a normal anatomy (OR 5.9; 95\% CI 4.3-8.1). ${ }^{25}$ A systematic review reported increased PTB rates before 37 weeks (risk ratio [RR] 2.14, 95\% CI 1.48-3.11; RR 2.97, 95\% CI 2.08-4.23) in women with (sub)septate uteri and unification defects (unicornuate, bicornuate, and didelphys uteri), respectively. ${ }^{26}$ At this moment, hysteroscopic resection of the septum is a subject of debate. There is no convincing evidence concerning its effectiveness and safety. An ongoing RCT assesses this procedure. ${ }^{27}$

\section{Prior excisional cervical procedures}

Women who had a prior excisional procedure for cervical dysplasia have an overall risk of spontaneous PTB before 35 weeks of $\sim 13 \%{ }^{28}$ Conner et al ${ }^{29}$ performed a meta-analysis assessing the association between loop electrosurgical excision procedure and PTB. They reported a higher risk of spontaneous PTB $<37$ weeks in the group that underwent a loop electrosurgical excision procedure (pooled RR 1.60; 95\% CI 0.99-2.55); however, this was not statistically significant. Danhof et a ${ }^{30}$ performed a meta-analysis comparing women treated for cervical intraepithelial neoplasia before or during pregnancy to women with an untreated cervical intraepithelial neoplasia. They reported a significantly higher risk for PTB in the treated group (OR 1.7; 95\% CI 1.0-2.7). The risk was highest in women treated during pregnancy (OR 6.5; 95\% CI 1.1-37).

\section{Obstetric history}

\section{Curettage in history}

Women with a previous pregnancy loss (either termination or miscarriage) managed by cervical dilatation and curettage are at higher risk for spontaneous PTB (OR 1.66; 95\% CI 1.14-2.42). The risk increased twofold in women with two curettage procedures. ${ }^{31}$ Lemmers et al ${ }^{32}$ performed a meta-analysis including 21 studies reporting on $1,853,017$ women. In women with a dilatation and curettage procedure, a higher risk of PTB before 37 weeks was reported, compared to the group with no such history (OR 1.29; 95\% CI 1.17-1.42). ORs for PTB <32 weeks (OR 1.69; 95\% CI 1.20-2.38) and $<28$ weeks (OR 1.47; 95\% CI 1.47-1.92) were even higher. A more recent metaanalysis by Saccone et al ${ }^{33}$ reported that a prior surgical management of either a spontaneous abortion (OR 1.19; 95\% CI 1.03-1.37) or an indicated termination of pregnancy (OR 1.52; 95\% CI 1.08-2.16) is an independent risk factor for a PTB. The exact mechanism that leads to the increased risk remains unclear, although mechanical damage to the cervix seems a logical explanation. A noninvasive management approach for termination of pregnancy or nonviable pregnancies has been proven a good alternative for mechanical procedures. Therefore, it is strongly recommended and may prevent future cases of PTB. National guidelines should strongly emphasize this association, and women should be counseled for a noninvasive management approach.

\section{Previous PTB}

A history of PTB is the most important risk factor for recurrence of PTB. The risk for a recurrent PTB increases if there is more than one PTB. Moreover, the risk is increased if the gestational age of the previous PTB was lower. ${ }^{34}$ Recurrence risk of a preterm singleton delivery before 37 weeks of gestation ranges from $15.8 \%$ to $30.2 \%$. In women with previous preterm twins, recurrence risk in a following singleton gestation is $\sim 10 \%$. For a following twin gestation after a previous preterm singleton delivery, the recurrence risk is $57 \%$ (95\% CI 51.9-61.9). ${ }^{35}$

\section{Current pregnancy}

Pregnancy interval

Both shorter and longer pregnancy intervals $(<18$ months and $>60$ months) have been associated with a higher risk of PTB. However, it is still unclear whether this association is the effect of confounding by other risk factors. ${ }^{36}$ So far, no causal effect between short or long pregnancy interval and 
adverse neonatal outcome can be determined. Women with a recent PTB should be counseled that a short pregnancy interval probably increases the risk of PTB.

\section{Multiple gestations}

In 2013, the twin birth rate in the US was 33.7 per 1,000 births. Women with a multiple gestation are known to be at increased risk of PTB. In 2013 in the USA, 57\% of twin gestation delivered before 37 weeks, of which 11\% delivered very premature (before 32 weeks). ${ }^{37}$ In 2013, a decline in the number of triplet and other high-order pregnancies was observed. This decline has been addressed to a change in assisted reproductive technology (ART) procedures. ${ }^{38}$ In the Netherlands, a single-embryo transfer policy has resulted in an impressive decrease of multiple pregnancies as a result of ART procedures. In 2014, 3.8\% of the pregnancies as a result of ART were a multiple gestation, compared to $22.2 \%$ in $2003 .{ }^{39}$ Global PTB rates can be further reduced by extensive implementation of single-embryo transfer.

\section{Screening for PTB}

Effective screening and prevention of PTB vary between the different pregnancy populations, and screening tools can be adjusted to the risk category of this pregnancy. Women with a singleton gestation without previous PTB have a lower risk for a PTB compared to women with a twin gestation. In women with a multiple gestation, almost $60 \%$ deliver premature. ${ }^{3}$ Women with a previous PTB have a significantly higher chance of a recurrence compared to women without PTB in the past $(21.7 \%$ vs $8.8 \% ; P \leq 0.001) .{ }^{40}$ In this review, we discuss both screening and prevention strategies that have shown to be effective in women with a singleton pregnancy without PTB, multiple pregnancies, and women with a previous PTB.

For an optimal prevention of PTB, risk stratification should be based on a combination of all risk factors including obstetric history and screening tools.

\section{Bacterial vaginosis}

Bacterial vaginosis is an abnormal vaginal condition that results from overgrowth of Gardnerella vaginalis, Mobiluncus, Bacteroides spp., and Mycoplasma hominis, which replace the normal vaginal lactobacilli. ${ }^{41}$ Bacterial vaginosis is associated with an increased risk of PTB. A metaanalysis in 2007 by Leitich et $\mathrm{al}^{42}$ in 30,518 women showed that bacterial vaginosis doubles the risk for spontaneous PTB in asymptomatic women (OR 2.16; 95\% CI 1.56-3.00). In women with a twin gestation, this association remains unclear.
A meta-analysis by Conde-Agudelo et al of three studies ${ }^{43-45}$ reported low predictive value of bacterial vaginosis in twin pregnancies with sensitivities and specificities between $0 \%$ and $23 \%$ and $78 \%$ and $82 \%$, respectively. Positive and negative likelihood ratios (LRs) ranged between 0.6 and 1.0 and 1.0 and $1.2 .^{46}$

Based on current literature, there is no evidence that all pregnancies should be screened for bacterial vaginosis. A Cochrane review from 2013 including 21 trials reported that no effect on the PTB rate before 37 weeks of gestation (RR 0.88; 95\% CI 0.71-1.09) was seen when asymptomatic bacterial vaginosis was treated in both low-risk and highrisk singleton pregnancies. ${ }^{47}$ However, Thinkhamrop et $\mathrm{al}^{48}$ showed beneficial effects of treatment in high-risk singleton pregnancies in a Cochrane review, with a reduction in PTB (RR 0.64; 95\% CI 0.47-0.88). Furthermore, Lamont et $\mathrm{al}^{49}$ conducted a systematic review and meta-analysis assessing the administration of clindamycin to women with bacterial vaginosis. This study comprised 2,346 women and showed a beneficial effect of clindamycin $<22$ weeks on both spontaneous PTB $<37$ weeks (RR 0.60; 95\% CI 0.42-0.86) and late miscarriages (RR $0.20 ; 95 \%$ CI $0.05-0.76$ ). This implies that screening for bacterial vaginosis with the use of a Nugent score test and adequate treatment of bacterial vaginosis with clindamycin in women with a history of PTB may be considered.

\section{Cervical length}

Women with a singleton pregnancy without previous PTB

A short mid-pregnancy cervical length is associated with a high risk of spontaneous PTB. ${ }^{50,51}$ The relative risk of preterm delivery increases as the length of the cervix shortens. A cervical length $<22 \mathrm{~mm}$ (fifth percentile) is associated with a relative risk of PTB of 9.49 with a $95 \%$ CI of $5.95-$ 15.15. A large study assessing predictive factors for PTB in a low-risk population revealed that cervical ultrasonography had the best sensitivity, almost $40 \%$. However, this still implicates a poor predictive value in a low-risk population. ${ }^{52}$

In a Dutch trial assessing the predictive capacity of cervical length screening for PTB, almost 12,000 women with a singleton gestation were screened. LRs for a cervical length between $30 \mathrm{~mm}$ and $35 \mathrm{~mm}$ were 2.0 (95\% CI 1.6-2.5) and 1.5 (95\% CI 0.97-2.2) for nulliparous women and multiparous women without a history of spontaneous PTB $<34$ weeks of gestation, respectively. ${ }^{53}$ Whether the introduction of universal cervical length screening will lead to a reduction in PTB is subject to debate. Recent studies have shown a 
reduction in the total number of PTBs and cost-effectiveness of this strategy. In our opinion, there is sufficient evidence to implement universal cervical length screening, as several therapeutic options in case of a short cervical length are present, such as progesterone or pessary.

\section{Women with uterine anomalies and/or prior excisional procedure}

In women with uterine anomalies, a cervical length $<25 \mathrm{~mm}$ is predictive for PTB $<35$ weeks $(\mathrm{LR}+8.1 ; 95 \% \mathrm{CI} 3.1-21) .{ }^{54}$ Miller and Grobman ${ }^{55}$ performed a retrospective cohort study in women who underwent a routine cervical assessment. Women with a prior excisional procedure more often had a short cervix $(<30 \mathrm{~mm})(6.5 \%$ vs $1.5 \%, P<0.001)$. In the study of Berghella et al, ${ }^{28}$ a cervical length $<25 \mathrm{~mm}$ was associated with a significant risk for PTB before 35 weeks (RR 4.74; 95\% CI 1.57-15.3) in women with a prior excisional procedure. Crane et $\mathrm{al}^{56}$ reported that cervical length $<30 \mathrm{~mm}$ after 24 weeks of pregnancy is associated with PTB before 37 weeks (OR 3.45; 95\% CI 1.28-10.0). However, these results are based on a small subgroup $(n=75)$ of women with a previous loop electrosurgical excision procedure. Cervical length screening at mid-pregnancy is advised in women with prior cervical excisional procedures or a uterine anomaly.

\section{Women with a multiple pregnancy without previous PTB}

A prospective study by Goldenberg et $\mathrm{al}^{45}$ in 1996 , evaluating screening for risk factors in twin pregnancies, showed that a cervical length $<25 \mathrm{~mm}$ at 24 weeks is associated with spontaneous PTB before 37 weeks (OR 6.9; 95\% CI 2.0-24.2). A meta-analysis by Conde-Agudelo et $\mathrm{al}^{57}$ in 3,213 asymptomatic women revealed that a mid-trimester cervical length $\leq 25 \mathrm{~mm}$ had a pooled positive LR of $9.6(95 \% \mathrm{CI}$ $5.8-14.8$ ) to predict early PTB before 28 weeks. In this group, a cervical length $\leq 20 \mathrm{~mm}$ was the most accurate in predicting PTB before 32 weeks and 34 weeks (positive LR 10.1 and 9.0 , respectively) ${ }^{57} \mathrm{In}$ twin pregnancies, routine screening for cervical length is still being debated. In our opinion, in view of the recent scientific progress showing a possible benefit in women with a short cervix of administration of progesterone or pessary, screening for cervical length at mid-pregnancy should be offered in multiple pregnancies. In case of a short cervix, women can have an informed choice to participate in ongoing trials assessing preventive strategies.

\section{Women with a previous PTB}

Since a short cervical length has been shown to be one of the best predictors in PTB, women with a previous preterm delivery are often offered screening for cervical length before 24 weeks pregnancy. A mid-trimester cervical length $<25 \mathrm{~mm}$ has an LR+ of 2.9 (95\% CI 2.1-3.9) in women with a previous PTB. The LR increased as the cervical length cutoff shortened. ${ }^{58}$ Berghella et $\mathrm{al}^{59}$ showed that the risk of a spontaneous PTB declined by $\sim 6 \%$ for each additional millimeter cervical length. In a study of Iams et al ${ }^{51}$ combining both cervical length measurement and fetal fibronectin, the recurrence risk increased as cervical length shortened in both fibronectin-positive and -negative women.

Therefore, we recommend screening for cervical length in this high-risk population.

\section{Fetal fibronectin}

Fetal fibronectin is a glycoprotein that is found in the extracellular matrix between the amniotic membranes and the decidua. It is hypothesized that damage to the fetal membranes may cause a higher concentration of fetal fibronectin in cervicovaginal secretions. Therefore, it is often used to predict delivery within 7 days in symptomatic women. ${ }^{60}$

\section{Women with a singleton pregnancy without previous PTB}

A prospective cohort by Goldenberg et $\mathrm{al}^{61}$ in 2,929 low-risk singleton pregnancies revealed an association between a positive fibronectin test and PTB before 28 weeks (sensitivity 0.63, specificity 0.98, and RR 59.2; 95\% CI 35.9-97.8) A secondary analysis in this cohort by Iams et al ${ }^{52}$ in 2,197 low-risk women showed that a positive fetal fibronectin assay is significantly related to PTB before 35 weeks (RR 8.2; 95\% CI 4.8-13.9); however, the test has a low sensitivity $(23.4 \%)$. Fetal fibronectin as a screening test in asymptomatic women is therefore not recommended.

\section{Women with uterine anomalies and/or prior excisional procedure}

There is no evidence for fetal fibronectin as a screening test in women with uterine anomalies or a prior excisional procedure.

\section{Women with a multiple pregnancy without previous PTB}

In multiple pregnancies, conflicting results have been published reporting the predictive value of fetal fibronectin. A retrospective cohort by Fox et $\mathrm{a}^{62}$ assessing the predictive value of a fetal fibronectin test in twin pregnancies with a normal cervical length $(>25 \mathrm{~mm})$ found an independent association between a positive fetal fibronectin test and PTB $<32$ weeks (OR 6.8; 95\% CI 1.42-32.2). 
Conde-Agudelo et a ${ }^{46}$ performed a systematic review and meta-analysis to evaluate the predictive test accuracy of fetal fibronectin in multiple gestations. This meta-analysis included 15 studies with 1,221 asymptomatic and symptomatic women. Among asymptomatic women with a multiple pregnancy, the pooled sensitivities and specificities of fetal fibronectin ranged from $33 \%$ to $45 \%$ and $80 \%$ to $94 \%$, respectively, for predicting PTB before 32 weeks, 34 weeks, and 37 weeks. LRs ranged between 2.0-5.5 and 0.68-0.76 for PTB $<32$ weeks, 34 weeks, and 37 weeks. ${ }^{46}$ This is low compared to the accuracy of mid-trimester cervical screening. Fetal fibronectin screening does not seem to add clinical value to cervical length screening in multiple pregnancies and is therefore not recommended.

\section{Women with a previous PTB}

There are conflicting results regarding the use of fetal fibronectin in women with a previous PTB. Iams et al concluded that in women with a prior PTB, fetal fibronectin was the most powerful single predictor. Predicted recurrence risk of spontaneous PTB before 35 weeks doubles in women with a positive fibronectin test, compared to those with a negative test. Women with a cervical length $<25 \mathrm{~mm}$ and a positive fibronectin test had the highest recurrence risk (64\%). ${ }^{51}$ However, a cohort of 176 high-risk singleton pregnancies by Romero et $\mathrm{al}^{63}$ did not show an association between a positive fetal fibronectin test and recurrent PTB before 34 weeks (OR 0.65; 95\% CI 0.043-9.7). Moreover, the positive and negative LRs were 1.22 and 0.98 , respectively, indicating a very low accuracy. In this high-risk group, it is therefore not recommended to routinely perform a fetal fibronectin test.

\section{Prevention of PTB}

Several preventive measures have been examined over the past decades. Certain risk factors, such as sociodemographic factors, cannot be adjusted; however, this information can be used to determine women's individual risk profile. Clinical caregivers can inform patients on their risks. There are potential preventive interventions, including progesterone, cervical pessary, and cerclage, that have been studied in different patient populations. In this section, we discuss these interventions and their application within the different patient categories.

\section{Progesterone}

Progesterone is a hormone known for its role in maintaining pregnancy. In the early stage of the pregnancy, this hormone is produced by the corpus luteum. ${ }^{64,65}$ Progesterone concentrations in peripheral blood drop before the onset of labor in most mammalian species. Nevertheless, this mechanism is not present in humans. ${ }^{66}$ It is known that administration of progesterone receptor antagonists to pregnant women causes cervical ripening and shortening and can lead to onset of labor. ${ }^{67,68}$ For this reason, it has been proposed that progesterone administration can prevent preterm cervical ripening.

\section{Women with a singleton pregnancy without previous PTB}

In a low-risk singleton population, multiple studies have assessed the effect of progesterone in reducing PTB. In 2013, an individual patient data meta-analysis (IPD meta-analysis) including women with a short cervix $(<25 \mathrm{~mm})$ showed a reduction of PTB $<28$ weeks of gestation (RR $0.51 ; 95 \%$ CI $0.31-0.85$ ), $<33$ weeks of gestation (RR $0.56 ; 95 \%$ CI $0.40-0.80$ ), and $<35$ weeks of pregnancy (RR $0.67 ; 95 \%$ CI $0.51-0.87)$. The composite neonatal morbidity and mortality were lower in the group that was using vaginal progesterone (RR 0.59; 95\% CI 0.38-0.91).$^{69}$ In 2013, a Cochrane metaanalysis including four trials involving 1,556 singleton gestations with a short cervix reported that women using vaginal progesterone were less likely to deliver before 34 weeks of gestation (RR 0.64 ; 95\% CI $0.45-0.90$ ). ${ }^{70}$ For neonatal outcomes (infant respiratory distress syndrome, mortality, sepsis, etc), no significant difference was identified. A recent randomized placebo-controlled trial by Norman et $\mathrm{al}^{71} \mathrm{com}$ prising 1,228 women assessed the effect of vaginal progesterone as prophylaxis for PTB and reported no reduction in PTB $<34$ weeks or fetal death (OR 0.69; 95\% CI 0.39-1.20) or composite adverse neonatal outcome (OR $0.54 ; 95 \%$ CI $0.25-1.16$ ) in the short cervix subgroup. However, neonatal death and brain injury on ultrasound, components of the composite outcome, were significantly reduced in the progesterone group. In addition, point estimates are in the direction of benefit of progesterone, similar to those reported in the Cochrane meta-analysis.

An individual participant data analysis can provide new information on the use of progesterone and overcome complexities such as different progestogens (vaginal or muscular), different inclusion criteria used in previous studies, and differences in reported outcomes.

\section{Women with a multiple pregnancy without previous PTB}

In 2013, a Cochrane meta-analysis involving 3,395 multiple pregnancies found no significant effect of vaginal 
progesterone on preventing PTB $<34$ weeks of gestation and perinatal death. ${ }^{70}$ Serra et al ${ }^{72}$ compared different dosages of progesterone (200 mg vs $400 \mathrm{mg}$ progesterone), and similar results were obtained in both groups. An IPD meta-analysis by Schuit et al, ${ }^{73}$ involving 13 trials and 3,768 women, showed no difference in adverse neonatal outcomes between the progesterone (both vaginal and 17-hydroxyprogesterone caproate) and control group. However, in a subgroup of women with a short cervix ( $\leq 25 \mathrm{~mm}$ ), vaginal progesterone reduced adverse neonatal outcomes, compared to the control group (RR 0.57; 95\% CI 0.47-0.70). Further research should focus on the effect of progesterone in women expecting multiples with a mid-trimester short cervix. At present, there is insufficient evidence to routinely prescribe progesterone to women with a multiple pregnancy and a short cervix. However, given the present evidence, we support the use of progesterone within the context of RCTs.

\section{Women with a previous PTB}

Research has shown that progesterone could reduce recurrence rates of spontaneous PTB.

In 2003, Meis et $\mathrm{al}^{74}$ performed a double-blind placebocontrolled trial involving 463 women with a history of spontaneous PTB. They reported a significant reduction in recurrence rate of $\mathrm{PTB}$ before 37 weeks in the progesterone group (RR 0.66; 95\% CI 0.54-0.81).

In contrast, the recent OPPTIMUM study did not find a beneficial effect of vaginal progesterone in women with a previous PTB before 34 weeks in terms of reduction of PTB $<34$ weeks or fetal death (OR 0.82; 95\% CI 0.58-1.16) and adverse cognitive outcome at 2 years of age (OR -0.14 ; $95 \%$ CI -2.79 to -2.52$)$. However, a positive effect was seen on the composite adverse neonatal outcome (OR 0.48; 95\% CI $0.29-0.79) .{ }^{71}$ In addition, no long-term harm of progesterone was reported since no demonstrable effect on cognitive scores was seen at 2 years of age.

The Cochrane meta-analysis by Dodd et $\mathrm{al}^{70}$ showed that progesterone, in women with a past history of spontaneous PTB, significantly reduced PTB before 34 weeks when compared to the control group (RR 0.31 ; 95\% CI 0.14-0.69). Moreover, there was an overall lower perinatal mortality (RR 0.50; 95\% CI 0.33-0.75) in the progesterone group.

So far, no difference in the effectiveness of both vaginal and muscular (17-hydroxyprogesterone caproate) progesterone has been found. In conclusion, given the available evidence and positive point estimates of the OPPTIMUM study, we strongly advice the use of progesterone in women with a previous PTB.

\section{Pessary}

The cervical pessary is a soft and flexible silicone device. It is folded and put around the cervix by a simple vaginal examination without causing any pain. Although the exact working mechanism is still unknown, pessaries may distribute the weight of the uterus on to the vaginal floor and relieve pressure on the internal os. Therefore, a pessary might prevent premature dilatation of the cervix and preterm rupture of the membranes. ${ }^{75}$ In addition, a pessary might support the immunological barrier between the chorion and vaginal microbiological flora, which helps to prevent PTB. ${ }^{76}$

\section{Women with a singleton pregnancy without previous PTB}

In a low-risk population with a short cervix, limited evidence is available for the prevention of PTB with a cervical pessary. A Spanish RCT by Goya et al $^{77}$ including 384 singleton pregnancies showed a significant reduction of preterm delivery before 34 weeks in the pessary group compared to the expectant management group (OR 0.18; 95\% CI 0.08-0.37) and reduction in PTB rates before 37 weeks (OR 0.19; 95\% CI 0.12-0.30). A smaller Chinese RCT of 108 women in the same year could not reproduce these results. PTB before 34 weeks occurred in $9.4 \%$ and $5.5 \%$ in the pessary and expectant management group, respectively $(P=0.46) .^{78}$ Both studies shared similarities as the inclusion period and the cutoff of the cervical length $(<25 \mathrm{~mm})$, however, with dissimilar results. In the Chinese study, lower PTB rates before 37 weeks were reported compared to those in the Spanish study ( $16.7 \%$ vs $40.5 \%$ ). Therefore, it might be more likely to find a beneficial effect in the Spanish group. Further research must confirm the efficacy of a cerclage pessary in preventing PTB in singletons without a previous PTB, but with a short mid-trimester cervix. In our opinion, at present, a pessary in women with a short cervix without a previous PTB should only be placed within the context of an RCT.

\section{Women with a multiple pregnancy without previous PTB}

There are conflicting results regarding the efficacy of a cervical pessary in preventing PTB in multiple gestations. A large RCT by Liem et al ${ }^{79}$ (PROTWIN) found an improvement of the neonatal outcome in a subgroup of 133 women with a cervical length $<38 \mathrm{~mm}$ ( 25 th percentile) (RR 0.40 ; 95\% CI 0.19-0.83). In this subgroup, PTB rates $<28$ weeks and $<34$ weeks of gestation were also lower in favor of the pessary group. In the total group of 808 twin gestations, neonatal outcome did not differ between the pessary and 
control group (RR 0.98; 95\% CI 0.69-1.39). In 2016, a per-protocol analysis with the original PROTWIN data was published, and this confirmed the principal findings of the intention-to-treat analysis. ${ }^{80}$ Moreover, a recent trial by Goya et a ${ }^{81}$ with 137 women with a multiple pregnancy with a short cervix $(<25 \mathrm{~mm})$ reported a significant reduction in PTB before 34 weeks of gestation in the pessary group compared to the control group (RR $0.41 ; 95 \%$ CI $0.22-0.76$ ). Pessary use was also associated with less children born with a birth weight $<2,500 \mathrm{~g}$ (RR 0.72; 95\% CI 0.54-0.97). Another recent trial, by Nicolaides et al, ${ }^{82}$ including 1,180 twin pregnancies without a specific cervical length cutoff, showed no effect of a cervical pessary on PTB rates $<34$ weeks (RR 1.05; 95\% CI 0.79-1.4) and adverse neonatal outcome (RR 1.09; 95\% CI 0.85-1.4). The post hoc analysis evaluating 214 women with a short cervix $(<25 \mathrm{~mm})$ did not change these results. At present, there is insufficient evidence to routinely place a pessary in women with a multiple pregnancy and a short cervix. However, given the present evidence, we support the use of pessaries within the context of RCTs.

\section{Women with a previous PTB}

In the group of women with a history of spontaneous PTB, pessaries have been less evaluated. In the Spanish PECEP trial, 41 singleton pregnancies with a previous PTB were included. Overall, this study showed a positive effect of the cervical pessary. Spontaneous delivery before 34 weeks of gestation was significantly less frequent in the pessary group than in the expectant management group (OR 0.18; 95\% CI 0.08-0.37), but no subgroup analysis has been performed for the group of women with a previous preterm. ${ }^{77}$ Alfirevic et $\mathrm{al}^{83}$ performed a study were they compared the effect of three management protocols in women with a previous PTB before 34 weeks and a short cervix. In this study, the outcomes of the 42 women in the Spanish PECEP trial were compared to 142 women with a cerclage (USA) and 59 women who received vaginal progesterone (UK). There were no statistically significant differences in perinatal losses, neonatal morbidity, and PTBs among the three groups. At this moment, there are ongoing RCTs evaluating the effect of a pessary in women with a previous preterm delivery and a short cervix. Results of these studies are needed to determine optimal management in this high-risk group. We support the evaluation of the pessary within the context of RCTs in women with a prior PTB.

\section{Cerclage}

A cervical cerclage is a surgical intervention that has been used widely in the management of pregnancies regarded as at high risk of preterm delivery. The cervical cerclage is a securing suture around the cervix to prevent cervical shortening and opening.

\section{Women with a singleton pregnancy without previous PTB}

So far, there is no evidence for the prevention of PTB in low-risk singletons with a short cervix only using a cervical cerclage. An RCT by To et $\mathrm{al}^{84}$ published in The Lancet in 2004 found no difference in the neonatal outcome and preterm delivery before 33 weeks. PTB rates before 33 weeks of gestation were similar in both groups, $22 \%$ (28 of 127) in the cerclage group versus $26 \%$ (33 of 126) in the control group (RR 0.84; 95\% CI 0.54-1.31). An IPD meta-analysis of four trials showed a reduction of PTB before 35 weeks of gestation (RR 0.74; 95\% CI 0.57-0.96). However, this meta-analysis also included women with a prior PTB. ${ }^{85} \mathrm{~A}$ meta-analysis from 2010 assessing the effect of a cerclage in women with a cervix $<25 \mathrm{~mm}$ showed no beneficial effect in preventing PTB before 35 weeks in the subgroup of women without a previous PTB (RR 0.84; 95\% CI 0.60-1.18). ${ }^{86}$ Therefore, a cerclage is not recommended in women with a short cervix without a prior PTB.

\section{Women with a multiple pregnancy without previous PTB}

Only limited data are available on the effect of a cervical cerclage to prevent PTB in multiple gestations. In 2015, a meta-analysis including 49 twin gestations with a short cervix $(<25 \mathrm{~mm})$ has been published. The authors show no significant reduction in PTB $<34$ weeks (OR 1.17; 95\% CI 0.23-3.79). ${ }^{87}$ Moreover, rates of very low birth weight $(<1,500 \mathrm{~g})$ (adjusted OR 2.22; 95\% CI 1.07-5.73) and of respiratory distress syndrome (adjusted OR 3.88; 95\% CI 1.09-21.03) were significantly higher in the cerclage group than in the control group. A Cochrane meta-analysis that included five trials with a total of 1,577 randomized women reported no difference in PTB $<34$ weeks (RR 1.16; 95\% CI 0.44-3.06) and no reduction in a composite of perinatal death and neonatal morbidity (RR 1.54; 95\% CI 0.58-4.11). ${ }^{88}$

A recent retrospective cohort of Roman et $\mathrm{al}^{89}$ in asymptomatic twin pregnancies with a short cervix $(<25 \mathrm{~mm})$ showed no difference in perinatal outcomes or PTB $<34$ weeks (OR 0.37; 95\% CI 0.16-1.1). In a subgroup analysis of women with a cervical length $<15 \mathrm{~mm}$, the cerclage was associated with a significantly decreased PTB rate $<34$ weeks by $49 \%$, and prolongation of the pregnancy by almost 4 weeks, compared to the controls. At present, there is not enough evidence 
that a cervical cerclage is beneficial in preventing PTB for multiple gestations and may even be harmful. It is therefore not recommended.

\section{Women with a previous PTB}

In women with a history of spontaneous PTB, two indications for a cerclage can be identified. History-indicated cerclages, also known as elective cerclages, and secondary cerclages, also known as ultrasound indicated (when cervical shortening is objectified).

\section{History-indicated cerclage - primary intervention}

The effectiveness of a primary cerclage has been assessed in a number of studies. In 1993, an international multicenter RCT included 1,292 unselected women with an indication for a primary cerclage. In this study, women in the cerclage group less often delivered before 33 weeks of gestation (OR 0.72 ; 95\% CI 0.53-0.97) compared to the expectant management group. In this study, a variety of indications for the cerclage were included such as previous PTB, but also twin pregnancy, prior cone biopsy, and uterine anomalies. ${ }^{90}$ A systematic review by Bachmann et $\mathrm{al}^{91}$ showed that an elective cervical cerclage has a significant effect in reducing spontaneous PTB $<34$ weeks. A meta-analysis was not possible due to the large differences in the quality of the studies. Further research with a focus on the identification of women who would benefit from a primary cerclage is recommended.

\section{Ultrasound-indicated cerclage - secondary intervention}

Women with a high risk based on obstetric history and a short mid-trimester cervix could benefit from a secondary cervical cerclage. Berghella et $\mathrm{al}^{92}$ performed a meta-analysis evaluating the effect of a cervical cerclage in women with a previous spontaneous PTB and a mid-trimester cervical length $<25 \mathrm{~mm}$. The authors showed a decline in the number of preterm deliveries before 35 weeks of gestation in the cerclage group compared to the control group (RR 0.70 ; 95\% CI 0.55-0.89). PTB rates before 37 weeks, 32 weeks, and 28 weeks were also significantly lower in the cerclage group. Moreover, the composite adverse neonatal outcome was significantly reduced in the cerclage group (RR 0.64 ; 95\% CI 0.45-0.91). A Cochrane review reported similar effects on PTB. Twelve studies involving 3,328 pregnant women were included. Compared to the control group, women in the cerclage group were less likely to deliver premature (RR 0.80; 95\% CI 0.69-0.9). Nevertheless, this review did not found a significant reduction in perinatal morbidity and mortality. Cervical cerclage was associated with a higher risk of maternal side effects (bleeding, pyrexia, and vaginal discharge) and higher cesarean section rates (RR 1.19; 95\% CI 1.01-1.40). ${ }^{93}$ In women with a previous PTB and a short cervix on ultrasound at mid-pregnancy, we support the use of a cerclage.

\section{Current challenges}

The reduction of PTB is an important goal for health care professionals and governments worldwide. A reduction in PTB leads to the best start in life for babies and is the best way to ensure lifelong health benefits. It is our obligation to inform women of reproductive ages on the influence they have on reducing PTBs by a healthy lifestyle. Furthermore, we have to convince our colleagues to only use ART techniques when necessary and perform single-embryo transfer in case of in vitro fertilization in order to further reduce multiple pregnancies. In addition, we should persuade our colleagues to install a more conservative approach in case of abortion or nonviable pregnancies, in order to reduce the number of PTBs as a result of curettages. It is our obligation to stress the need for government campaigns to inform the public on PTB and the lifelong consequences. We must urge fundraisers to invest in research into pathophysiology and treatment of PTB in order to give babies the best start in life.

\section{New developments}

We describe several new developments in screening for PTB and preventive strategies.

\section{Biomarkers}

One of the new focuses of research is using biomarkers as a screening target for PTB. ${ }^{94}$ A recent study by Cantonwine et $\mathrm{al}^{95}$ identified functional proteomic biomarkers that are unique in their expression at the first trimester (10-12 weeks) in women who will deliver spontaneously $\leq 34$ weeks of gestation. In the future, after further validation, these factors might allow stratification of patients at risk for PTB and identify women who might benefit from preventive strategies.

\section{Probiotics}

Probiotics as a preventive strategy for PTB have been reported in several studies, with conflicting results. A Norwegian study showed a possible preventive effect of probiotics through milk intake on spontaneous PTB ${ }^{96}$ However, a meta-analysis by Dugoua et $\mathrm{al}^{97}$ in 2009 revealed no difference in gestational age in the probiotic group compared to the no-probiotics group (mean difference 0.4 weeks, 95\% CI -0.4 to 1.2 ). Only three RCTs included in this meta-analysis reported 
gestational age; therefore, further sufficiently powered randomized trials are necessary.

\section{Genetics}

Evidence suggests that important risk factors for PTB may be grounded in genetics. Epidemiological studies have shown that mothers who were born preterm themselves, or have sisters or maternal half-sisters who delivered preterm, are at higher risk of PTB.$^{98}$ Segregation analysis of traits in families and concordance in parturition timing in twin gestations revealed that both maternal and fetal genetic factors account for the variation in gestational age at delivery. Maternal genetic factors accounted for $20.6 \%$ (95\% CI 18.1-23.2) and fetal genetic factors for $13.1 \%$ (95\% CI 6.8-19.4). ${ }^{99} \mathrm{New}$ available technologies, such as genome-wide single nucleotide polymorphism array and whole-exome sequencing to identify rare alleles, can potentially help discovering genes and pathways that play a key role in human birth timing. ${ }^{100}$

\section{Ongoing trials}

\section{Cervical pessary and progesterone}

Multiple ongoing trials are assessing preventive strategies for PTB. A case series of 43 women described a combination of cervical pessaries with intravaginal micronized progesterone to prevent PTB. ${ }^{101}$ A more recent article by Stricker et $\mathrm{al}^{102}$ in 2016 reported combined treatment with vaginal progesterone and pessary in 53 women. The combined strategy did not reduce the PTB rates before 28 weeks, 32 weeks, 34 weeks, and 37 weeks. Compared to the pessary alone group, the composite adverse neonatal outcome was similar in both the progesterone and pessary groups (OR 1.03; 95\% CI 0.34-3.09). ${ }^{102}$ These studies lack power because of the small groups; therefore, it remains unclear whether this combined therapy might lead to a reduction of spontaneous PTB.

Furthermore, an ongoing study evaluates whether a cervical pessary can replace a cervical cerclage in women with at least one previous PTB and an indication for a primary or secondary cerclage in terms of effectiveness. The results of this study ( $\mathrm{PC}$-study ${ }^{103}$ ) help to determine the best treatment for preventing PTB in this high-risk group.

\section{Aspirin}

A Dutch ongoing trial (APRIL ${ }^{104}$ ) assesses low-dose aspirin as a preventive strategy for recurrent PTB. Several secondary studies and IPD meta-analysis showed a positive effect of low-dose aspirin on spontaneous PTB; therefore, this intervention seems promising. ${ }^{105,106}$

\section{Future prospects}

As described in this review, new developments in obstetric care will have to provide better information on who is at risk for preterm delivery and how to prevent this. To develop the best possible care for pregnant women and their newborns, it is important to get a better grip on what is known already and define the gaps in the knowledge. To do so, outcomes must be measured in a universal way. The GoNet (Global Obstetrics Network) initiative was founded by international investigators to standardize outcomes for PTB studies. A core outcome set is developed with an international multidisciplinary perspective to ensure that data from PTB trials can be compared and combined. ${ }^{107}$ This combination and pooling of data can be used in the performance of an individual participant data meta-analysis. ${ }^{108}$ Ongoing (prospective) IPD meta-analysis on pessaries in both singletons and twins and an IPD metaanalysis on progesterone in singletons will hopefully give new perspective on how to prevent PTB in these groups.

It is known that implementation of new findings often is a time-consuming process. With the results of the ongoing IPD meta-analysis, new evidence-based national and international guidelines will be developed. In these guidelines, the implementation of universal cervical length screening and use of progesterone in women with a previous PTB must be brought to attention.

Since research is developing and more techniques to prevent PTB will be assessed, patients must be informed about these findings. Patient organizations can help by informing their members on ongoing research and new insights. In this way, patients can make an informed choice to participate in ongoing studies and discuss new strategies with their caregivers. Furthermore, patients must be part of the development of new guidelines and patient representatives can help doctors to find acceptable preventive strategies. A strong collaboration between doctors, patients' organizations, pharmaceutical companies, and (international) governments can improve prevention of spontaneous PTB.

\section{Conclusion}

Prevention of PTB is one of the main obstetric goals. For an optimal prevention of PTB, risk stratification should be based on a combination of (maternal) risk factors, obstetric history, and screening tools. In singleton or multiple pregnancies with a short cervix, without previous PTB, a pessary or progesterone might prevent PTB. In women with a (recurrent) PTB in the past, progesterone and a cerclage may prevent recurrence. The effect of a pessary in these high-risk women 
is currently being studied. Furthermore, (ongoing) research evaluates the role of biomarkers, probiotics, and genetics in PTB. Researchers, doctors, patient's organizations, and governments must collaborate in the prevention of PTB. By doing so, we give babies the best start in life and ensure lifelong health benefits.

\section{Acknowledgment}

E Pajkrt received funding from a Dutch health foundation founded by health insurance company Achmea (Stichting Achmea Gezondheidszorg).

\section{Disclosure}

The authors report no conflicts of interest in this work.

\section{References}

1. Beck S, Wojdyla D, Say L, et al. The worldwide incidence of preterm birth: a systematic review of maternal mortality and morbidity. Bull World Health Organ. 2010;88(1):31-38.

2. WHO: recommended definitions, terminology and format for statistical tables related to the perinatal period and use of a new certificate for cause of perinatal deaths. Modifications recommended by FIGO as amended October 14, 1976. Acta Obstet Gynecol Scand. 1977;56(3):247-253.

3. Goldenberg RL, Culhane JF, Iams JD, Romero R. Epidemiology and causes of preterm birth. Lancet. 2008;371(9606):75-84.

4. Lawn JE, Cousens S, Zupan J. Lancet neonatal survival steering T. 4 million neonatal deaths: when? Where? Why? Lancet. 2005;365(9462) 891-900

5. Simmons LE, Rubens CE, Darmstadt GL, Gravett MG. Preventing preterm birth and neonatal mortality: exploring the epidemiology, causes, and interventions. Semin Perinatol. 2010;34(6):408-415.

6. Patel RM. Short- and long-term outcomes for extremely preterm infants. Am J Perinatol. 2016;33(3):318-328.

7. Stoll BJ, Hansen NI, Bell EF, et al. Trends in care practices, morbidity, and mortality of extremely preterm neonates, 1993-2012. JAMA. 2015;314(10):1039-1051.

8. Slattery MM, Morrison JJ. Preterm delivery. Lancet. 2002;360(9344): 1489-1497.

9. Mangham LJ, Petrou S, Doyle LW, Draper ES, Marlow N. The cost of preterm birth throughout childhood in England and Wales. Pediatrics. 2009;123(2):e312-e327.

10. Nations $U$ [webpage on the Internet]. Reduce by Two Thirds, between 1990 and 2015, the Under-Five Mortality Rate. Available from: http://www.un.org/millenniumgoals/childhealth.shtml. Accessed January 16, 2016.

11. Schaaf JM, Liem SM, Mol BW, Abu-Hanna A, Ravelli AC. Ethnic and racial disparities in the risk of preterm birth: a systematic review and meta-analysis. Am J Perinatol. 2013;30(6):433-450.

12. Schaaf JM, Mol BW, Abu-Hanna A, Ravelli AC. Ethnic disparities in the risk of adverse neonatal outcome after spontaneous preterm birth. Acta Obstet Gynecol Scand. 2012;91(12):1402-1408.

13. Lynch AM, Hart JE, Agwu OC, Fisher BM, West NA, Gibbs RS. Association of extremes of prepregnancy BMI with the clinical presentations of preterm birth. Am J Obstet Gynecol. 2014;210(5):428.e1-428.e9.

14. Salihu HM, Mbah AK, Alio AP, Clayton HB, Lynch O. Low prepregnancy body mass index and risk of medically indicated versus spontaneous preterm singleton birth. Eur J Obstet Gynecol Reprod Biol. 2009;144(2):119-123.

15. Simpson WJ. A preliminary report on cigarette smoking and the incidence of prematurity. Am J Obstet Gynecol. 1957;73(4):807-815.
16. Underwood P, Hester LL, Laffitte T Jr, Gregg KV. The relationship of smoking to the outcome of pregnancy. Am J Obstet Gynecol. 1965;91: $270-276$.

17. Shah NR, Bracken MB. A systematic review and meta-analysis of prospective studies on the association between maternal cigarette smoking and preterm delivery. Am J Obstet Gynecol. 2000;182(2):465-472.

18. McCowan LM, Dekker GA, Chan E, et al. Spontaneous preterm birth and small for gestational age infants in women who stop smoking early in pregnancy: prospective cohort study. BMJ. 2009;338:b1081.

19. Been JV, Nurmatov UB, Cox B, Nawrot TS, van Schayck CP, Sheikh A. Effect of smoke-free legislation on perinatal and child health: a systematic review and meta-analysis. Lancet. 2014;383(9928):1549-1560.

20. Iams JD, Romero R, Culhane JF, Goldenberg RL. Primary, secondary, and tertiary interventions to reduce the morbidity and mortality of preterm birth. Lancet. 2008;371(9607):164-175.

21. Pretorius C, Jagatt A, Lamont RF. The relationship between periodontal disease, bacterial vaginosis, and preterm birth. J Perinat Med. 2007;35(2):93-99.

22. Michalowicz BS, Hodges JS, DiAngelis AJ, et al. Treatment of periodontal disease and the risk of preterm birth. $N$ Engl J Med. 2006; 355(18): 1885-1894.

23. Newnham JP, Newnham IA, Ball CM, et al. Treatment of periodontal disease during pregnancy: a randomized controlled trial. Obstet Gynecol. 2009;114(6):1239-1248.

24. Polyzos NP, Polyzos IP, Mauri D, et al. Effect of periodontal disease treatment during pregnancy on preterm birth incidence: a metaanalysis of randomized trials. Am J Obstet Gynecol. 2009;200(3):225-232.

25. Hua M, Odibo AO, Longman RE, Macones GA, Roehl KA, Cahill AG. Congenital uterine anomalies and adverse pregnancy outcomes. Am J Obstet Gynecol. 2011;205(6):558.e551-558.e555.

26. Chan YY, Jayaprakasan K, Tan A, Thornton JG, Coomarasamy A, RaineFenning NJ. Reproductive outcomes in women with congenital uterine anomalies: a systematic review. Ultrasound Obstet Gynecol. 2011;38(4): 371-382.

27. TRUST [webpage on the Internet]. TRUST Study: The Randomized Uterine Septum Transsection Trial. Available from: http://www.studiesobsgyn.n1/trust. Accessed March 20, 2016.

28. Berghella V, Pereira L, Gariepy A, Simonazzi G. Prior cone biopsy: prediction of preterm birth by cervical ultrasound. Am J Obstet Gynecol. 2004;191(4):1393-1397.

29. Conner SN, Frey HA, Cahill AG, Macones GA, Colditz GA, Tuuli MG. Loop electrosurgical excision procedure and risk of preterm birth: a systematic review and meta-analysis. Obstet Gynecol. 2014;123(4): $752-761$.

30. Danhof NA, Kamphuis EI, Limpens J, van Lonkhuijzen LR, Pajkrt E, Mol BW. The risk of preterm birth of treated versus untreated cervical intraepithelial neoplasia (CIN): a systematic review and meta-analysis. Eur J Obstet Gynecol Reprod Biol. 2015;188:24-33.

31. McCarthy FP, Khashan AS, North RA, et al. Pregnancy loss managed by cervical dilatation and curettage increases the risk of spontaneous preterm birth. Hum Reprod. 2013;28(12):3197-3206.

32. Lemmers M, Verschoor MA, Hooker AB, et al. Dilatation and curettage increases the risk of subsequent preterm birth: a systematic review and meta-analysis. Hum Reprod. 2016;31(1):34-45.

33. Saccone G, Perriera L, Berghella V. Prior uterine evacuation of pregnancy as independent risk factor for preterm birth: a systematic review and metaanalysis. Am J Obstet Gynecol. 2016;214(5):572-591.

34. Iams JD, Berghella V. Care for women with prior preterm birth. Am J Obstet Gynecol. 2010;203(2):89-100.

35. Kazemier BM, Buijs PE, Mignini L, et al; EBM CONNECT. Impact of obstetric history on the risk of spontaneous preterm birth in singleton and multiple pregnancies: a systematic review. BJOG. 2014;121(10): 1197-1208; discussion 1209.

36. Conde-Agudelo A, Rosas-Bermudez A, Kafury-Goeta AC. Birth spacing and risk of adverse perinatal outcomes: a meta-analysis. JAMA. 2006;295(15):1809-1823. 
37. Martin JA, Hamilton BE, Osterman MJ, Curtin SC, Matthews TJ. Births: final data for 2013. Natl Vital Stat Rep. 2015;64(1):1-65.

38. Practice Committee of American Society for Reproductive Medicine; Practice Committee of Society for Assisted Reproductive Technology. Criteria for number of embryos to transfer: a committee opinion. Fertil Steril. 2013;99(1):44-46.

39. nvog.nl [webpage on the internet]. NVOG Nederlandse Vereniging Voor Obstetrie en Gynaecologie. [Dutch Society of Obstetrics and Gynaecology]. Available from: http://www.nvog.nl//Sites/Files/0000004608_ IVF_cijfers_2014_per_kliniek[1][1].pdf. Accessed March 1, 2016.

40. Mercer BM, Goldenberg RL, Moawad AH, et al. The preterm prediction study: effect of gestational age and cause of preterm birth on subsequent obstetric outcome. National Institute of Child Health and Human Development Maternal-Fetal Medicine Units Network. Am J Obstet Gynecol. 1999;181(5 pt 1):1216-1221.

41. Leitich H, Bodner-Adler B, Brunbauer M, Kaider A, Egarter C, Husslein P. Bacterial vaginosis as a risk factor for preterm delivery: a meta-analysis. Am J Obstet Gynecol. 2003;189(1):139-147.

42. Leitich $\mathrm{H}$, Kiss $\mathrm{H}$. Asymptomatic bacterial vaginosis and intermediate flora as risk factors for adverse pregnancy outcome. Best Pract Res Clin Obstet Gynaecol. 2007;21(3):375-390.

43. Ruiz RJ, Fullerton J, Brown CE. The utility of fFN for the prediction of preterm birth in twin gestations. J Obstet Gynecol Neonatal Nurs. 2004;33(4):446-454.

44. Wennerholm UB, Holm B, Mattsby-Baltzer I, et al. Fetal fibronectin, endotoxin, bacterial vaginosis and cervical length as predictors of preterm birth and neonatal morbidity in twin pregnancies. $\mathrm{Br} J$ Obstet Gynaecol. 1997;104(12):1398-1404.

45. Goldenberg RL, Iams JD, Miodovnik M, et al. The preterm prediction study: risk factors in twin gestations. Am J Obstet Gynecol. 1996; 175(4, pt 1):1047-1053.

46. Conde-Agudelo A, Romero R. Cervicovaginal fetal fibronectin for the prediction of spontaneous preterm birth in multiple pregnancies: a systematic review and meta-analysis. J Matern Fetal Neonatal Med. 2010;23(12):1365-1376.

47. Brocklehurst $\mathrm{P}$, Gordon A, Heatley E, Milan SJ. Antibiotics for treating bacterial vaginosis in pregnancy. Cochrane Database Syst Rev. 2013;1: CD000262.

48. Thinkhamrop J, Hofmeyr GJ, Adetoro O, Lumbiganon P, Ota E. Antibiotic prophylaxis during the second and third trimester to reduce adverse pregnancy outcomes and morbidity. Cochrane Database Syst Rev. 2015;6:CD002250.

49. Lamont RF, Nhan-Chang CL, Sobel JD, Workowski K, Conde-Agudelo A, Romero R. Treatment of abnormal vaginal flora in early pregnancy with clindamycin for the prevention of spontaneous preterm birth: a systematic review and metaanalysis. Am JObstet Gynecol. 2011;205(3): $177-190$.

50. Iams JD, Goldenberg RL, Meis PJ, et al. The length of the cervix and the risk of spontaneous premature delivery. National Institute of Child Health and Human Development Maternal Fetal Medicine Unit Network. N Engl J Med. 1996;334(9):567-572.

51. Iams JD, Goldenberg RL, Mercer BM, et al. The Preterm Prediction Study: recurrence risk of spontaneous preterm birth. National Institute of Child Health and Human Development Maternal-Fetal Medicine Units Network. Am J Obstet Gynecol. 1998;178(5):1035-1040.

52. Iams JD, Goldenberg RL, Mercer BM, et al. The preterm prediction study: can low-risk women destined for spontaneous preterm birth be identified? Am J Obstet Gynecol. 2001;184(4):652-655.

53. van der Ven J, van Os MA, Kazemier BM, et al. The capacity of midpregnancy cervical length to predict preterm birth in low-risk women: a national cohort study. Acta Obstet Gynecol Scand. 2015;94(11): 1223-1234.

54. Airoldi J, Berghella V, Sehdev H, Ludmir J. Transvaginal ultrasonography of the cervix to predict preterm birth in women with uterine anomalies. Obstet Gynecol. 2005;106(3):553-556.

55. Miller ES, Grobman WA. The association between cervical excisional procedures, midtrimester cervical length, and preterm birth. Am JObstet Gynecol. 2014;211(3):242.e241-242.e244.
56. Crane JM, Delaney T, Hutchens D. Transvaginal ultrasonography in the prediction of preterm birth after treatment for cervical intraepithelial neoplasia. Obstet Gynecol. 2006;107(1):37-44.

57. Conde-Agudelo A, Romero R, Hassan SS, Yeo L. Transvaginal sonographic cervical length for the prediction of spontaneous preterm birth in twin pregnancies: a systematic review and metaanalysis. Am J Obstet Gynecol. 2010;203(2):128.e1-128.e12.

58. Crane JM, Hutchens D. Transvaginal sonographic measurement of cervical length to predict preterm birth in asymptomatic women at increased risk: a systematic review. Ultrasound Obstet Gynecol. 2008;31(5): 579-587.

59. Berghella V. Gestational age at Cervical Length Measurement and incidence of preterm birth. Obstet Gynecol. 2007;110(2):311-317.

60. Vis JY, van Baaren GJ, Wilms FF, et al. Randomized comparison of nifedipine and placebo in fibronectin-negative women with symptoms of preterm labor and a short cervix (APOSTEL-I Trial). Am J Perinatol. 2015;32(5):451-460.

61. Goldenberg RL, Mercer BM, Meis PJ, Copper RL, Das A, McNellis D. The preterm prediction study: fetal fibronectin testing and spontaneous preterm birth. Obstet Gynecol. 1996;87(5, pt 1):643-648.

62. Fox NS, Rebarber A, Roman AS, Klauser CK, Saltzman DH. The significance of a positive fetal fibronectin in the setting of a normal cervical length in twin pregnancies. Am J Perinatol. 2012;29(4): 267-272.

63. Romero J, Rebarber A, Saltzman DH, Schwartz R, Peress D, Fox NS. The prediction of recurrent preterm birth in patients on 17-alphahydroxyprogesterone caproate using serial fetal fibronectin and cervical length. Am J Obstet Gynecol. 2012;207(1):51.e51-51.e55.

64. Csapo AI, Pulkkinen MO, Ruttner B, Sauvage JP, Wiest WG. The significance of the human corpus luteum in pregnancy maintenance. I. Preliminary studies. Am J Obstet Gynecol. 1972;112(8):1061-1067.

65. Csapo AI, Pulkkinen MO, Wiest WG. Effects of luteectomy and progesterone replacement therapy in early pregnant patients. Am J Obstet Gynecol. 1973;115(6):759-765.

66. Smith R, Mesiano S, McGrath S. Hormone trajectories leading to human birth. Regul Pept. 2002;108(2-3):159-164.

67. Word RA, Li XH, Hnat M, Carrick K. Dynamics of cervical remodeling during pregnancy and parturition: mechanisms and current concepts. Semin Reprod Med. 2007;25(1):69-79.

68. Permezel M. The antiprogesterone steroid, RU 486 (mifepristone). Aust N Z J Obstet Gynaecol. 1990;30(1):77-80.

69. Romero R, Nicolaides K, Conde-Agudelo A, et al. Vaginal progesterone in women with an asymptomatic sonographic short cervix in the midtrimester decreases preterm delivery and neonatal morbidity: a systematic review and metaanalysis of individual patient data. Am J Obstet Gynecol. 2012;206(2):124.e1-124.e19.

70. Dodd JM, Jones L, Flenady V, Cincotta R, Crowther CA. Prenatal administration of progesterone for preventing preterm birth in women considered to be at risk of preterm birth. Cochrane Database Syst Rev. 2013;7:CD004947.

71. Norman JE, Marlow N, Messow CM, et al. Vaginal progesterone prophylaxis for preterm birth (the OPPTIMUM study): a multicentre, randomised, double-blind trial. Lancet. 2016;387(10033):2106-2116.

72. Serra V, Perales A, Meseguer J, et al. Increased doses of vaginal progesterone for the prevention of preterm birth in twin pregnancies: a randomised controlled double-blind multicentre trial. BJOG. 2013;120(1): $50-57$.

73. Schuit E, Stock S, Rode L, et al. Effectiveness of progestogens to improve perinatal outcome in twin pregnancies: an individual participant data meta-analysis. BJOG. 2015;122(1):27-37.

74. Meis PJ, Klebanoff M, Thom E, et al. Prevention of recurrent preterm delivery by 17 alpha-hydroxyprogesterone caproate. $N$ Engl J Med. 2003;348(24):2379-2385

75. Vitsky M. Simple treatment of the incompetent cervical os. Am J Obstet Gynecol. 1961;81:1194-1197.

76. Abdel-Aleem H, Shaaban OM, Abdel-Aleem MA. Cervical pessary for preventing preterm birth. Cochrane Database Syst Rev. 2010;9: CD007873. 
77. Goya M, Pratcorona L, Merced C, et al. Cervical pessary in pregnant women with a short cervix (PECEP): an open-label randomised controlled trial. Lancet. 2012;379(9828):1800-1806.

78. Hui SY, Chor CM, Lau TK, Lao TT, Leung TY. Cerclage pessary for preventing preterm birth in women with a singleton pregnancy and a short cervix at 20 to 24 weeks: a randomized controlled trial. Am J Perinatol. 2013;30(4):283-288.

79. Liem S, Schuit E, Hegeman M, et al. Cervical pessaries for prevention of preterm birth in women with a multiple pregnancy (ProTWIN): a multicentre, open-label randomised controlled trial. Lancet. 2013;382:1341-1349.

80. Liem S, Schuit E, Van Pampus M, et al. Cervical pessaries to prevent preterm birth in women with a multiple pregnancy: a per-protocol analysis of a randomized clinical trial. Acta Obstet Gynecol Scand. 2016;95(4):444-451.

81. Goya M, de la Calle M, Pratcorona L, et al. Cervical pessary to prevent preterm birth in women with twin gestation and sonographic short cervix: a multicenter randomized controlled trial (PECEP-Twins). Am J Obstet Gynecol. 2016;214(2):145-152.

82. Nicolaides KH, Syngelaki A, Poon LC, et al. Cervical pessary placement for prevention of preterm birth in unselected twin pregnancies:a randomized controlled trial. Am J Obstet Gynecol. 2016;214(1):3.e1-3.e9.

83. Alfirevic Z, Owen J, Carreras Moratonas E, Sharp AN, Szychowski JM, Goya M. Vaginal progesterone, cerclage or cervical pessary for preventing preterm birth in asymptomatic singleton pregnant women with a history of preterm birth and a sonographic short cervix. Ultrasound Obstet Gynecol. 2013;41(2):146-151.

84. To MS, Alfirevic Z, Heath VC, et al. Cervical cerclage for prevention of preterm delivery in women with short cervix: randomised controlled trial. Lancet. 2004;363(9424):1849-1853.

85. Berghella V, Odibo AO, To MS, Rust OA, Althuisius SM. Cerclage for short cervix on ultrasonography: meta-analysis of trials using individual patient-level data. Obstet Gynecol. 2005;106(1):181-189.

86. Berghella V, Keeler SM, To MS, Althuisius SM, Rust OA. Effectiveness of cerclage according to severity of cervical length shortening: a meta-analysis. Ultrasound Obstet Gynecol. 2010;35(4):468-473.

87. Saccone G, Rust O, Althuisius S, Roman A, Berghella V. Cerclage for short cervix in twin pregnancies: systematic review and meta-analysis of randomized trials using individual patient-level data. Acta Obstet Gynecol Scand. 2015;94(4):352-358.

88. Rafael TJ, Berghella V, Alfirevic Z. Cervical stitch (cerclage) for preventing preterm birth in multiple pregnancy. Cochrane Database Syst Rev. 2014;9:CD009166.

89. Roman A, Rochelson B, Fox NS, et al. Efficacy of ultrasound-indicated cerclage in twin pregnancies. Am J Obstet Gynecol. 2015;212(6):788. e781-788.e786.

90. Final report of the Medical Research Council/Royal College of Obstetricians and Gynaecologists multicentre randomised trial of cervical cerclage. MRC/RCOG Working Party on Cervical Cerclage. Br J Obstet Gynaecol. 1993;100(6):516-523.

91. Bachmann LM, Coomarasamy A, Honest H, Khan KS. Elective cervical cerclage for prevention of preterm birth: a systematic review. Acta Obstet Gynecol Scand. 2003;82(5):398-404.

92. Berghella V, Rafael TJ, Szychowski JM, Rust OA, Owen J. Cerclage for short cervix on ultrasonography in women with singleton gestations and previous preterm birth: a meta-analysis. Obstet Gynecol. 2011;117(3): 663-671.

International Journal of Women's Health

\section{Publish your work in this journal}

The International Journal of Women's Health is an international, peerreviewed open-access journal publishing original research, reports, editorials, reviews and commentaries on all aspects of women's healthcare including gynecology, obstetrics, and breast cancer. The manuscript management system is completely online and includes
93. Alfirevic Z, Stampalija T, Roberts D, Jorgensen AL. Cervical stitch (cerclage) for preventing preterm birth in singleton pregnancy. Cochrane Database Syst Rev. 2012;4:CD008991.

94. Heng YJ, Liong S, Permezel M, Rice GE, Di Quinzio MK, Georgiou HM. Human cervicovaginal fluid biomarkers to predict term and preterm labor. Front Physiol. 2015;6:151.

95. Cantonwine DE, Zhang Z, Rosenblatt K, et al. Evaluation of proteomic biomarkers associated with circulating microparticles as an effective means to stratify the risk of spontaneous preterm birth. Am J Obstet Gynecol. 2016;214(5):631.e1-631.e11.

96. Myhre R, Brantsaeter AL, Myking S, et al. Intake of probiotic food and risk of spontaneous preterm delivery. Am J Clin Nutr. 2011;93(1): 151-157.

97. Dugoua JJ, Machado M, Zhu X, Chen X, Koren G, Einarson TR Probiotic safety in pregnancy: a systematic review and meta-analysis of randomized controlled trials of Lactobacillus, Bifidobacterium, and Saccharomyces spp. J Obstet Gynaecol Can. 2009;31(6):542-552.

98. Boyd HA, Poulsen G, Wohlfahrt J, Murray JC, Feenstra B, Melbye M. Maternal contributions to preterm delivery. Am J Epidemiol. 2009; 170(11):1358-1364.

99. York TP, Eaves LJ, Lichtenstein P, et al. Fetal and maternal genes' influence on gestational age in a quantitative genetic analysis of 244,000 Swedish births. Am J Epidemiol. 2013;178(4):543-550.

100. Monangi NK, Brockway HM, House M, Zhang G, Muglia LJ. The genetics of preterm birth: progress and promise. Semin Perinatol. 2015;39(8):574-583.

101. Zimerman AL, Neeman O, Wiener Y, Maymon R, Arie H. [First year experience using arabin cervical pessary with intravaginal micronized progesterone for the prevention of preterm birth in patients with midtrimester short cervix]. Harefuah. 2014;153(2):79-82, 127.

102. Stricker N, Timmesfeld N, Kyvernitakis I, Goerges J, Arabin B. Vaginal progesterone combined with cervical pessary: a chance for pregnancies at risk for preterm birth? Am J Obstet Gynecol. 2016;214(6): 739.e1-739.e10.

103. PC-study [webpage on the Internet]. Pessary or Cerclage to Prevent Preterm Delivery in Women with Short Cervical Length and a History of Preterm Birth. Available from: http://www.studies-obsgyn.nl/PC. Accessed February 23, 2016

104. APRIL [webpage on the Internet]. Low dose aspirin in the Prevention of Recurrent Spontaneous Preterm Labour. Available from: http://www. studies-obsgyn.nl/april. Accessed February 22, 2016.

105. Allshouse AA, Jessel RH, Heyborne KD. The impact of low-dose aspirin on preterm birth: secondary analysis of a randomized controlled trial. J Perinatol. 2016;36(6):427-431.

106. van Vliet EOG, Mol BWJ, Askie LA, Oudijk MA. Antiplatelet agents and the prevention of spontaneous preterm birth: a meta-analysis of individual participant data. Annual of The Perinatal Society of Australia and New Zealand (PSANZ); April 21, 2015; Crown Promenade, Melbourne, Australia.

107. van't Hooft J, Duffy JM, Daly M, et al. A core outcome set for evaluation of interventions to prevent preterm birth. Obstet Gynecol. 2016;127(1):49-58.

108. Riley RD, Lambert PC, Abo-Zaid G. Meta-analysis of individual participant data: rationale, conduct, and reporting. BMJ. 2010;340:c221.

a very quick and fair peer-review system, which is all easy to use. Visit http://www.dovepress.com/testimonials.php to read real quotes from published authors. 